\title{
A "Turn-On" Fluorescent Sensor for the elective Hg(II) Detection in Aqueous Media Based on Metal-Induced Dye Formation
}

\author{
Yonggang Zhao, Zhihua Lin, Chunying Duan*, Cheng He and Qingjin Meng* \\ State Key Laboratory of Fine Chemicals, Dalian University of Technology, Dalian, \\ 116012,China.E-mail:cyduan@dlut.edu.cn.
}

\section{Supporting Information}

\section{General notes and procedures}

All metal ions used are $\mathrm{Hg}(\mathrm{II}), \mathrm{Li}(\mathrm{I}), \mathrm{Na}(\mathrm{I}), \mathrm{K}(\mathrm{I}), \mathrm{Mg}(\mathrm{II}), \mathrm{Ba}(\mathrm{II}), \mathrm{Ca}(\mathrm{II}), \mathrm{Cr}(\mathrm{III}), \mathrm{Mn}(\mathrm{II})$, $\mathrm{Fe}(\mathrm{II}), \mathrm{Co}(\mathrm{II}), \mathrm{Ni}(\mathrm{II}), \mathrm{Zn}(\mathrm{II}), \mathrm{Cd}(\mathrm{II}), \mathrm{Pb}(\mathrm{II}), \mathrm{Ag}(\mathrm{I})$ in the form of their nitrate salts. UV-vis spectra and fluorescence spectra were carried out in water-methanol $(90 / 10 \mathrm{v} / \mathrm{v})$ at room temperature, except the titration for new cycliazation product HL. UV-vis and Fluorometric titration method: A stock solution of $\mathbf{H}_{2} \mathbf{L}^{1}\left(5.0 \times 10^{-5} \mathrm{~mol} / \mathrm{L}\right), \mathbf{H L}\left(5.0 \times 10^{-5} \mathrm{~mol} / \mathrm{L}\right)$ and stock solutions $\left(2.0 \times 10^{-2}\right.$ $\mathrm{mol} / \mathrm{L}, 0.01 \mathrm{~mol} / \mathrm{L}$ for $\left.\mathrm{Hg}\left(\mathrm{NO}_{3}\right)_{2} \cdot 0.5 \mathrm{H}_{2} \mathrm{O}\right)$ of the selected metal ions were prepared. The solutions of $\mathbf{H}_{2} \mathbf{L}^{1}$ and $\mathbf{H L}$ were respectively titrated with the different stock solutions of metal ions. The intensity and band shift changes of the absorption bands and emission bands were monitored. 


\section{Fluorescent titration spectra of $\mathrm{H}_{2} \mathrm{~L}^{1}$ with addition of $\mathrm{Hg}(\mathrm{II})$}
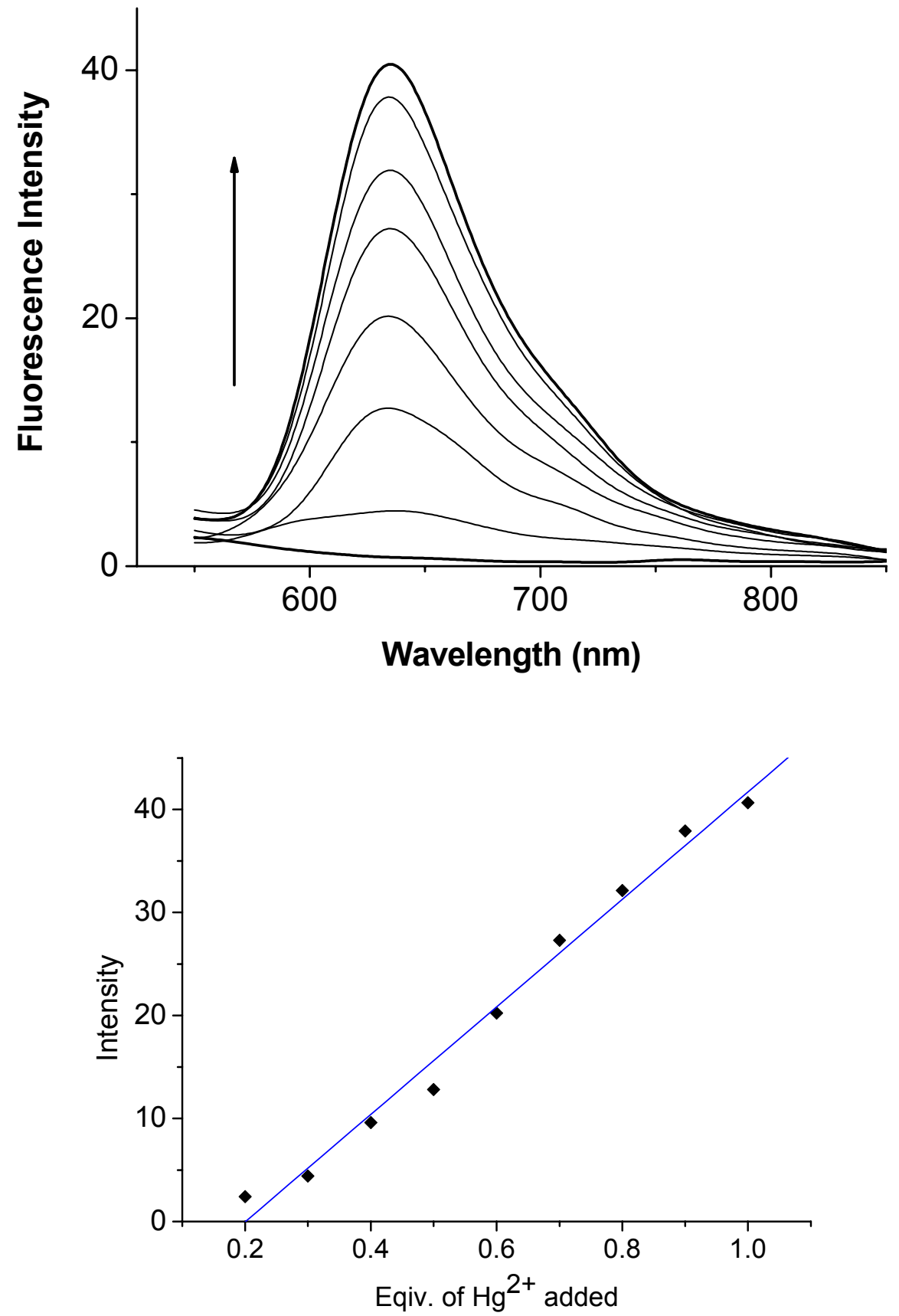

Figure S1 Luminescent titration of $\mathbf{H}_{2} \mathbf{L}^{1}\left(5.0 \times 10^{-5} \mathrm{M}\right)$ in $\mathrm{H}_{2} \mathrm{O} / \mathrm{CH}_{3} \mathrm{OH}(90: 10 \mathrm{v} / \mathrm{v})$ upon addition of $\mathrm{Hg}(\mathrm{II})$, excited at $380 \mathrm{~nm}$ (top) and the fluorescence titration curve at $635 \mathrm{~nm}$ (bottom). 


\section{UV-vis and fluorescent titration of $\mathrm{H}_{2} \mathrm{~L}^{1}$ upon addition of $\mathrm{Zn}$ (II)}
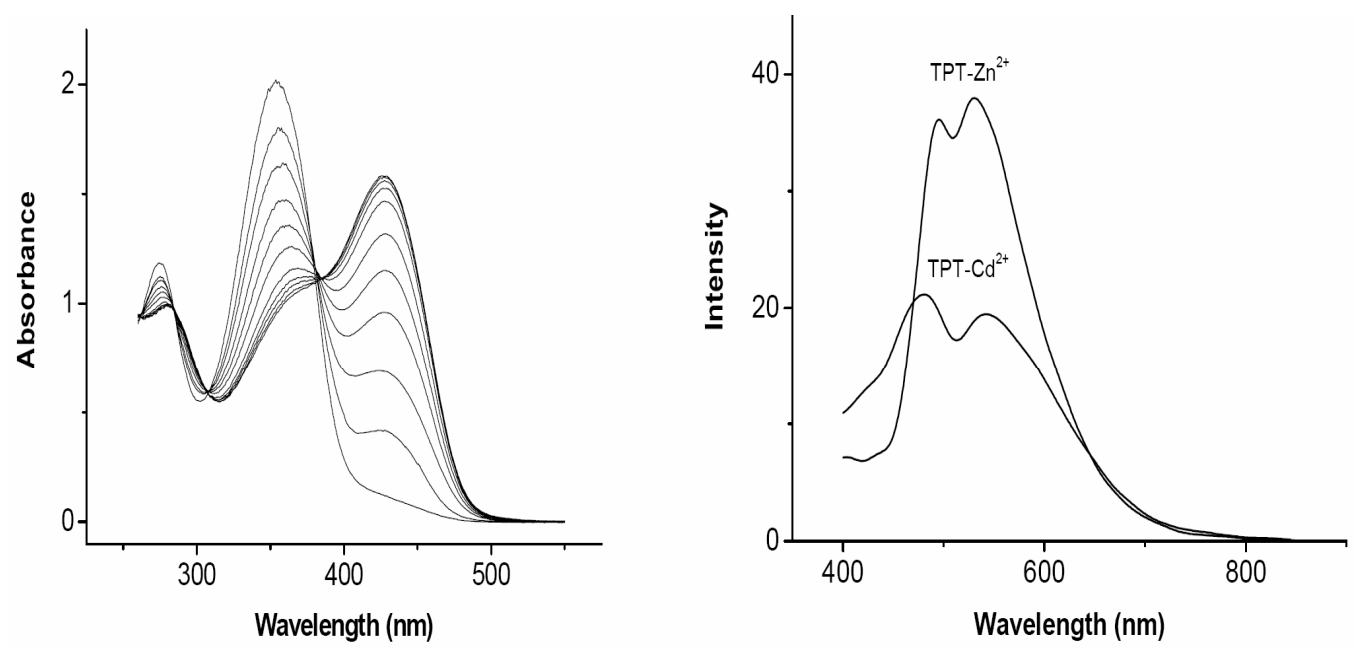

Figure S2 left: UV-vis titration spectra for $\mathbf{H}_{2} \mathbf{L}^{\mathbf{1}}\left(5.0 \times 10^{-5} \mathrm{M}\right)$ in water-methnol $(90 / 10 \mathrm{v} / \mathrm{v})$ with addition of $\mathrm{Zn}(\mathrm{II})$; right: fluorescence spectra $(\lambda=380 \mathrm{~nm})$ for $\left[\mathbf{H}_{2} \mathbf{L}^{1}-\mathrm{Zn}(\mathrm{II})\right]$ and $\left[\mathbf{H}_{2} \mathbf{L}^{1}-\mathrm{Cd}(\mathrm{II})\right]$. 


\section{${ }^{1}$ H NMR spectrum of the cyclization product HL}<smiles></smiles>

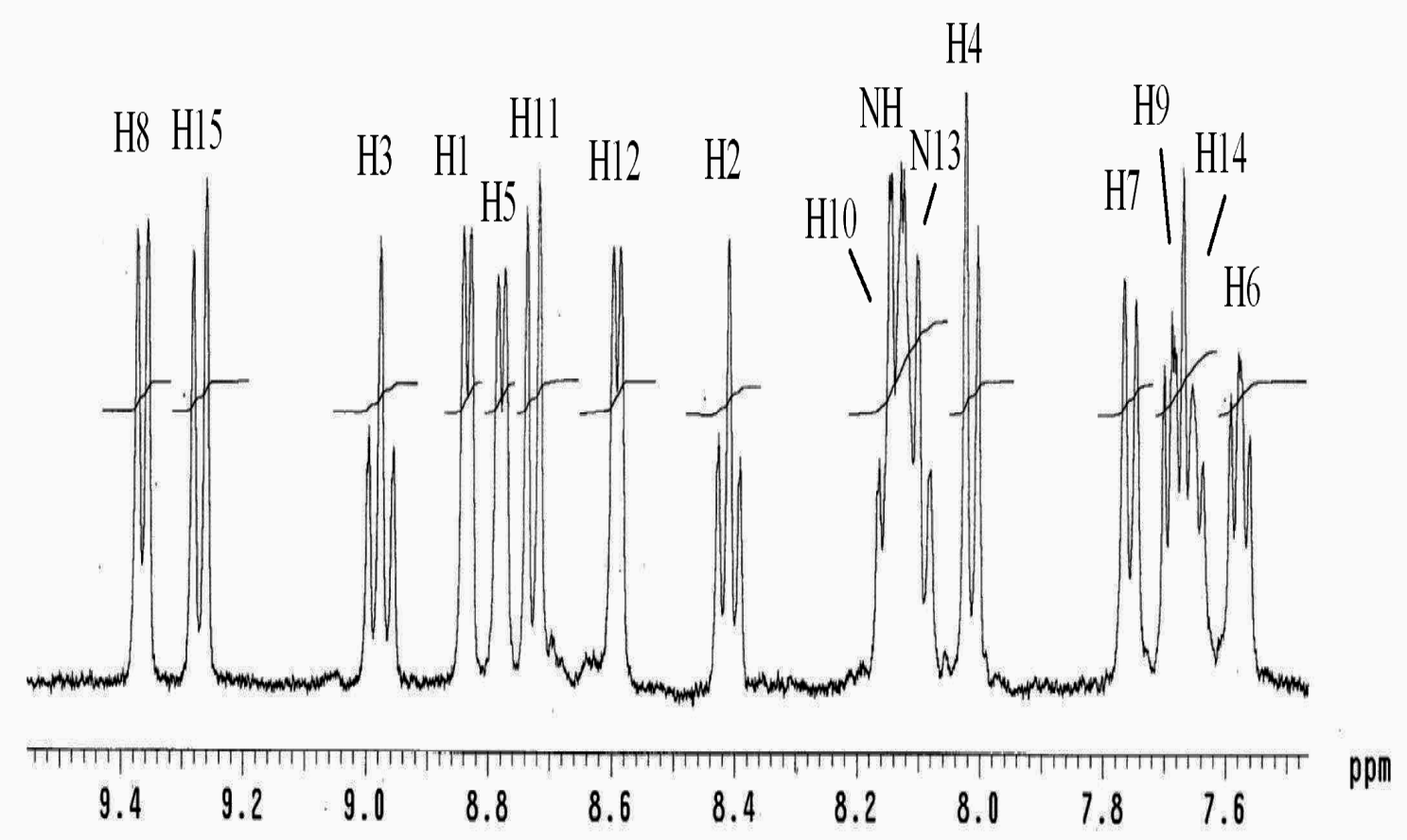

Figure S3 ${ }^{1} \mathrm{H}$ NMR spectrum of the the cyclization product $\mathbf{H L}$ in $d_{6}$-DMSO 
Fluorescent titrations of the cyclization product HL upon addition of $\mathrm{Hg}\left(\mathrm{NO}_{3}\right)_{2} \cdot \mathbf{0 . 5} \mathrm{H}_{2} \mathrm{O}$

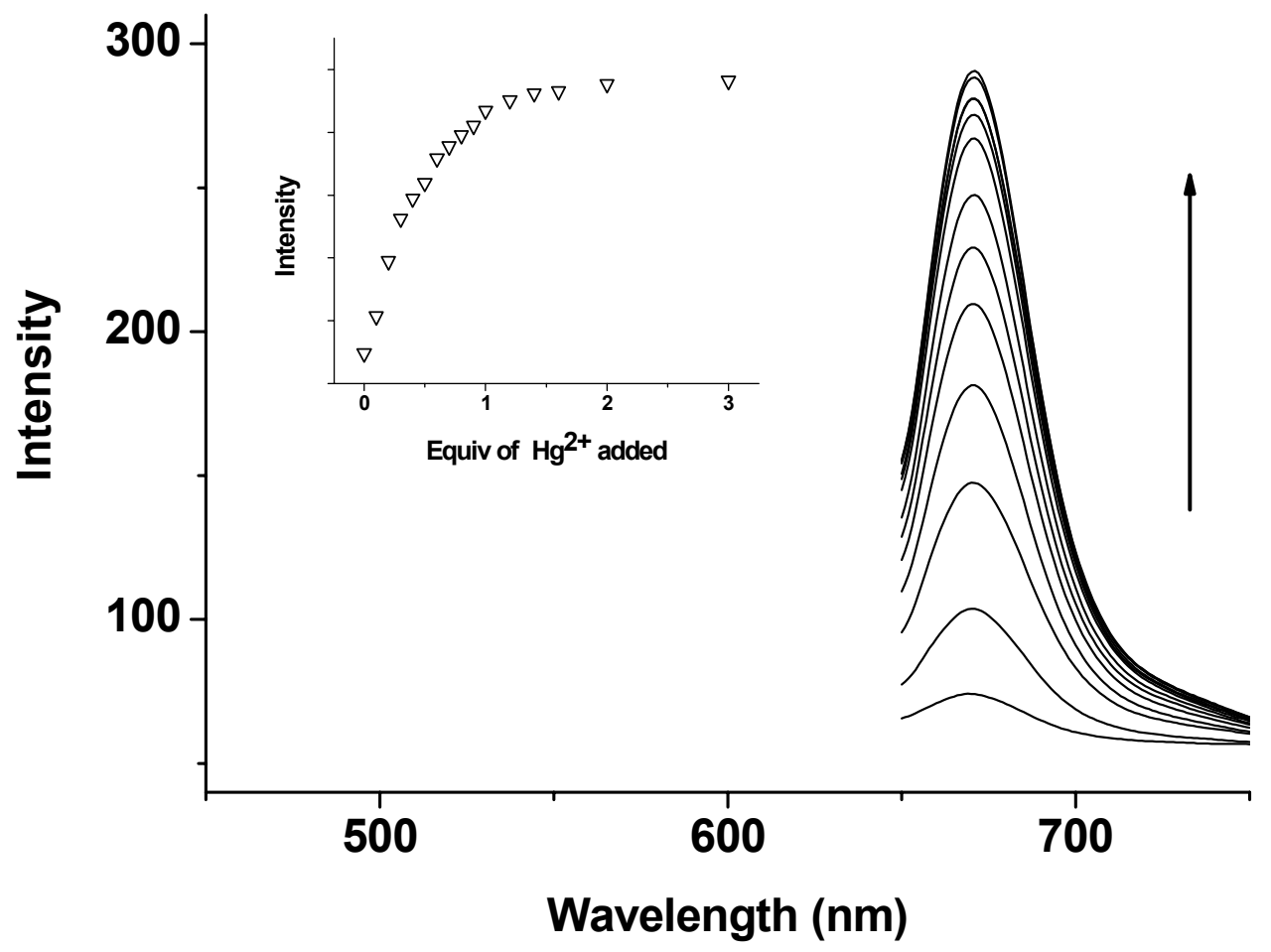

Figure S4 Fluorescent titrations of the cyclization product $\mathbf{H L}\left(5.0 \times 10^{-5} \mathrm{M}\right)$ in DMSO upon addition of $\mathrm{Hg}(\mathrm{II})$. The inset shows the titration profiles at $670 \mathrm{~nm}$. 